\title{
Elektrikli Taşıtlarda Kullanılan İndüksiyon / Sabit Mıknatıslı Motor Sürücülerinin Simülasyonu ve Motor Dinamiklerinin Analizi
}

\author{
Simulation of Induction / Permanent Magnet Motor Drives Used in Electric Vehicles and \\ Analysis of Motor Dynamics
}

\author{
Koray Yılmaz KAYA ${ }^{1,2}$ (D) , İsmail KIYAK \\ ${ }^{1}$ Akrm Metal ARGE Merkezi, 34956, İstanbul, Türkiye \\ ${ }^{2}$ Marmara Üniversitesi, Fen Bilimleri Entitüsü, Elektrik Elektronik Mühendisliği Bölümü, 34722, İstanbul, \\ Türkiye \\ ${ }^{3}$ Marmara Üniversitesi, Teknoloji Fakültesi, Elektrik Elektronik Mühendisliği Bölümü, 34722, İstanbul, Türkiye
}

$\ddot{O} z$

Bu makalede, elektrikli araçlarda kullanılan motor çeşitlerinden sincap kafesli indüksiyon motor ve sabit mıknatıslı senkron motorun yapısal özellikleri ve hız dinamikleri karşılaştırılmıştır. Karşılaştırılmanın doğru yapılabilmesi için aynı tork altında benzer parametrelere sahip motorlar, alan odaklı kontrol (FOC) yöntemi ile sürülmüştür. Motorların hızlanma ve yavaşlama esnasında geçici hal durumları simülasyon ortamında incelemiş ve karşılaştırılmıştır. Sonuçlar göstermektedir ki indüksiyon motorları hız değişimlerine daha çabuk tepki gösterirken, sabit mıknatıslı motorlar daha geç tepki vermektedir. Bunun yanında sabit mıknatıslı motorların tork gerektiren kalkış anlarında daha iyi performans gösterdiği anlaşılmıştır. Simülasyon PSIM programı kullanılarak gerçekleştirilmiştir. Simülasyonda kullanılan motor sürücülerin anahtarlama frekansı, giriş gerilimleri vb. parametreler aynı seçilmiştir.

Anahtar Kelimeler: İndüksiyon Motor ile Sabit Mıknatıslı Senkron Motorun performans karşılaştırması, PSIM, FOC kontrol yöntemi.

\begin{abstract}
In this paper, structural characteristics and speed dynamics of squirrel cage induction motor and permanent magnet synchronous motor, used in electric vehicles are compared. The motors with similar parameters under the same torque have been driven by the field oriented control (FOC) method in order to ensure correct comparison. Transient conditions of the motors during acceleration and deceleration were examined and compared in simulation. The results show that the induction motors react more quickly to the speed changes, whereas the permanent magnet motors react more late. In addition, it is understood that permanent magnet motors perform better during torque-demanding moments. Simulation was performed via PSIM program. The parameters such as switching frequency, input voltage were selected the same in motor driver simulations.

Keywords: Performance comparison of Induction Motor and Permanent Magnet Synchronous Motor, PSIM, FOC control method.

\section{GIRIŞ}

İlk elektrikli taşıt 19. Yüzyıl başlarında icat edilmiştir. Fakat bu yıllardaki motor, elektronik ve batarya teknolojisi yeterince gelişmemiş olması, taşıtların menzilini oldukça kısaltmıştır. Bununla birlikte ham petrolün keşfi ile içten yanmalı motorlar aktif hale gelmiştir ve bu taşıtlar hem ucuz hem de daha verimli olarak tasarlanabilmiştir. 20. Yüzyılın ortalarından itibaren fosil yakıtlı araçların egzoz emisyon sorunu yüzünden elektrikli araçlar tekrar gündeme gelmiş ve bu taşıtlar üzerine günümüze kadar birçok yeni tasarım yapılmıştır.
\end{abstract}

Günümüzde ise batarya, elektronik ve motor teknolojilerinin gelişmesi sayesinde elektrikli taşıtlar tekrar popüler olmuştur. Özelikle motor teknolojisinin gelişimi sayesinde elektrikli taşıtların ilk icat edildiği yıllarda kullanılan 
DC motorların yanında artık birden farklı teknolojiye sahip AC motorlarda kullanılmaya başlanmıştır. Sabit miknatıslı motorlar, indüksiyon motorlar ve relüktans motorları bunlara örnek olarak gösterilebilir.

Elektrikli taşıtlarda sık sık sabit mıknatıslı (PM) ve indüksiyon motorlar(IM) kullanılmaktadır (Zhu \& Howe, 2007), (Chau, Chan, \& Liu, 2008), (Buyukdegirmenci, Bazzi, \& Krein, 2014). İndüksiyon motorlar, sürücülerinin arıza durumunda doğal olarak uyartılmamış olduklarından taşıt üreticileri tarafindan güvenli bulunmakta iken sabit mıknatıslı motorlar ise yüksek tork yoğunlukları ve verimleri sayesinde indüksiyon motorlara göre daha iyi özelliklere sahip motorlar olarak kabul edilmektedir (Pellegrino, Vagati, Boazzo, \& Guglielmi, 2012), (Chau, 2016). Sabit mıknatıs motorları arasında, hem yüzeye monte PM (SPM) hem de iç PM (IPM) tipleri çekiş için uyarlanmıştır (El-Refaie \& Jahns, 2008). Çekiş için uyarlanan SPM motorlar, konsantre stator sargilarına, çok kısa sargı uç bağlantılarına ve kolay stator yapısına sahiptirler (El-Refaie \& Jahns, 2005).

Bu makalede, sabit mıknatıslı motor ile indüksiyon motor arasında karşılaştırma yapılmış ve her iki motorun PSIM simülasyon programında sabit torktaki hız tepkileri karşılaştırılmıştır. PSIM, özellikle elektrikli sürücüler ve güç elektroniği için tasarlanmış bir simülasyon yazılımıdır ve araştırma amaçlı yapılan çalışmalarda etkili olduğu kanıtlanmıştır (Kristiansen \& Steinsland, 2018).

\section{SABİT MIKNATISLI MOTOR İLE INNDÜKSIYON MOTORUN KARŞILAŞTIRMASI}

\subsection{Mimari Olarak Karşılaştırma}

Elektrikli araçlarda sıkça tercih edilen iki motor türü olan sabit mıknatıslı senkron motorun ve sincap kafesli indüksiyon asenkron motorun mimari yapıları Şekil 1 'de gösterildiği gibidir.

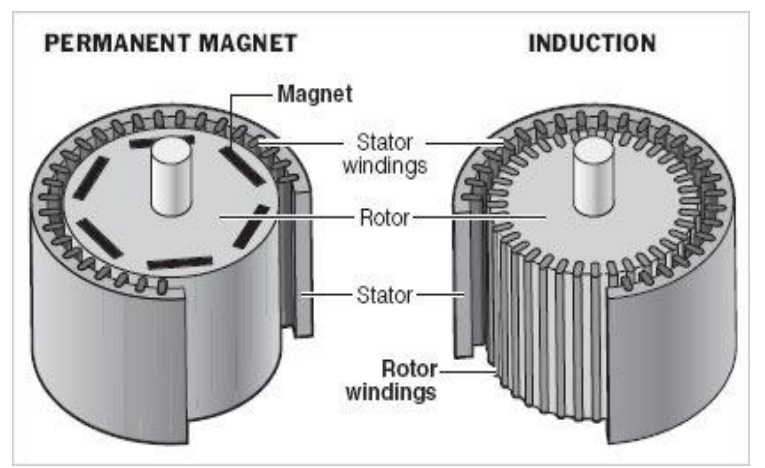

Şekil 1. İndüksiyon motoru ve sabit mıknatıslı motorun mimari olarak karşılaştırılması (Westenhaus, 2010).
Sabit miknatıslı motorun rotor kısmına özel bir materyalden yapılmış olan doğal olarak kuvvetli akıya sahip mıknatıslar yerleştirilmiştir. Mıknatıs materyali olarak önceleri sertleştirilmiş çelik kullanılırken son zamanlarda alüminyum nikel ve kobalt alaşımları (ALNICO), stronsiyum ferrit veya baryum ferrit (Ferrit), samaryum kobaltı (ilk nesil nadir toprak miknatısı) (SmCo) ve neodim demir-bor (ikinci nesil nadir toprak mıknatıs) (NdFeB) geliştirilmiş ve kullanılmıştır (Kiran, Nair, \& Lakshmi, 2016). Bu mıknatıslar sayesinde statoru uyartılmış bir Sabit Mıknatıslı motor senkron olarak çalıştırılabilmektedir. Ayrıca bu motorların tork uygulamalarında öne çıkmasının sebebi de özel mıknatıslara sahip olmasıdır. Sabit miknatıslı motorlar tork uygulamalarında indüksiyon motorlarına karşı güçlü bir rakiptir (Hashemnia \& Asaei, 2008). Son yıllarda bu motorlar elektrikli taşıtlarda çekiş uygulamalarında istenen motor türü olmuştur (Zhang, Cao, \& Morrow, 2015), (Bălţăţanu \& Florea, 2013).

İndüksiyon motorunda ise rotor k1smı da sargılardan oluştuğundan dolayı stator sargıları uyarıldığında rotor sargıları gerilim endüklemiş olur. Bundan dolayı indüksiyon motorlarındaki rotor stator döner alanını bir miktar kayma ile asenkron olarak takip eder. İndüksiyon motorlarında mıknatıs yoktur ve güçlü bir yapıdadır. Bu motorların stator ve rotor kısımlarının her ikisi de 1sındığından dolayı soğutmaya ihtiyaç duyması motorun özelliklerini sinırlamaktadır (Yang, Shang, Brown, \& Krishnamurthy, 2015). İndüksiyon motorun ana avantajları ise basit mimarisi, kolay bakımı, düşük kurulum maliyeti ve yüksek güvenilirliktir (Qinghua, 2005).

\subsection{Motor Performans Karşılaștırması}

Endüksiyon motoru ile Sabit miknatıslı motor performans değerlendirmesi olarak hı, verimlilik, güvenilirlik, güç yoğunluğu, doğruluk ve maliyet olarak karşılaştırılmıştır (Murphy, 2012).

\subsubsection{Hiz}

PMSM'lar servo motor ve indüksiyon motor hızlarına yaklaşık olarak ulaşabilmektedirler. İndüksiyon motorların kullanım hız aralıkları ise PMSM motorlara göre daha azdır.

\subsubsection{Verimlilik}

PMSM motorlar sabit mıknatısları sayesinde soğuk çalışabilirler. Dolayısıyla verimleri yüksektir. İndüksiyon motorları ise rotoru sargılı olduğundan dolayı çalışma esnasında ısınma problemleri yaşar ve bundan dolayı verimleri düşüktür.

\subsubsection{Güvenilirlik}

İndüksiyon motorlarda özellikle sargılardaki yüksek sıcaklık nedeniyle sargı izolasyonları zamanla yıpranır ve bu motorun tahrip olmasina sebep olur. PMSM'larda ise düşük çalışma sıcakları sayesinde 
sargılardaki izolasyon çok uzun süre bozulmadığından motor ömürleri uzun olur.

\subsubsection{Güç yoğunluğu}

İndüksiyon motorlarında sincap kafesli rotor mimarisinden dolayı doğal olarak güç yoğunluğu sınırlanmış olur. $\mathrm{Bu}$ sebepten dolayı indüksiyon motorlar tork uygulamalarından ziyade hiz uygulamalarında daha çok tercih edilir. Sabit mıknatıslı motorlar ise mıknatısların doğal bir akıya sahip olmaları sayesinde güç yoğunluğu oldukça fazladır. Bu motorlarda yüksek torklara elde edilebilir.

\subsubsection{Doğruluk}

Endüksiyon motorlarda, FOC (Field Oriented Control) ve Vektör kontrollü sayesinde doğruluk sağlanırken, sabit miknatıslı motorlarda harici geri besleme olmadan motorun tam doğruluğunu bulmak ve konumlandırmak zor olabilir.

\subsubsection{Maliyet}

Endüksiyon motorlarda kurulum maliyeti normal düzeyde iken, işletim maliyeti ısınma problemleri yüzünden yüksektir. Sabit mıknatıslı motorlarda ise mıknatıs maliyetlerinden dolayı kurulum maliyeti yüksektir. Fakat mıknatısların verimli olması ve motorun uzun ömürlü olması sayesinde işletme maliyetleri düşüktür.

\section{SİMÜLASYONLARIN INCELENMESI}

$\mathrm{Bu}$ çalışmada indüksiyon motorları ve sabit mıknatıslı motorların aynı torktaki hız değişimlerine verdiği tepkiler simülasyon ortamında incelenmiştir. Simülasyon programı olarak PSIM kullanılmıştır. Sabit miknatıslı senkron motor "Hız Geri Beslemeli PWM Kontrol” yöntemi ile Şekil 2 'de gösterildiği gibi sürülmüştür. İndüksiyon motoru ise " Alan Odaklı Kontrol (Field Oriented Control)" yöntemi ile Şekil 3 'te gösterildiği sürülmüştür. Simülasyonların daha rahat anlaşılması için " Alan Odaklı Kontrol (Field Oriented Control)" yöntemi ayrıntılı olarak incelenmiştir.

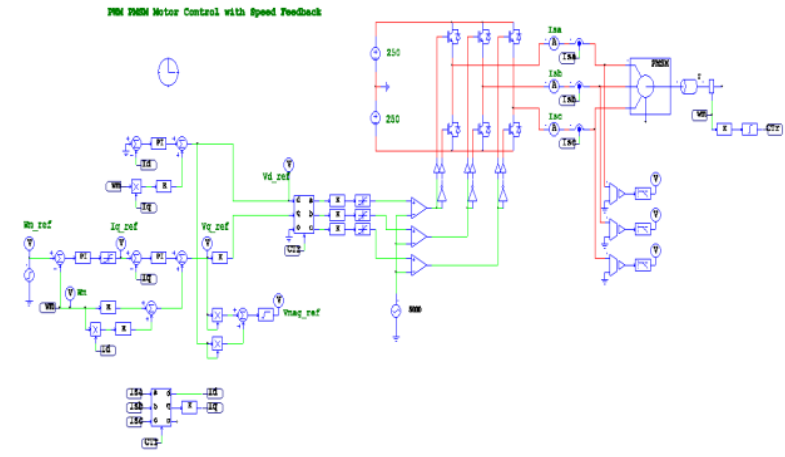

Şekil 2. PMSM 'un hız geri beslemesi ile PWM kontrolü simülasyon şeması

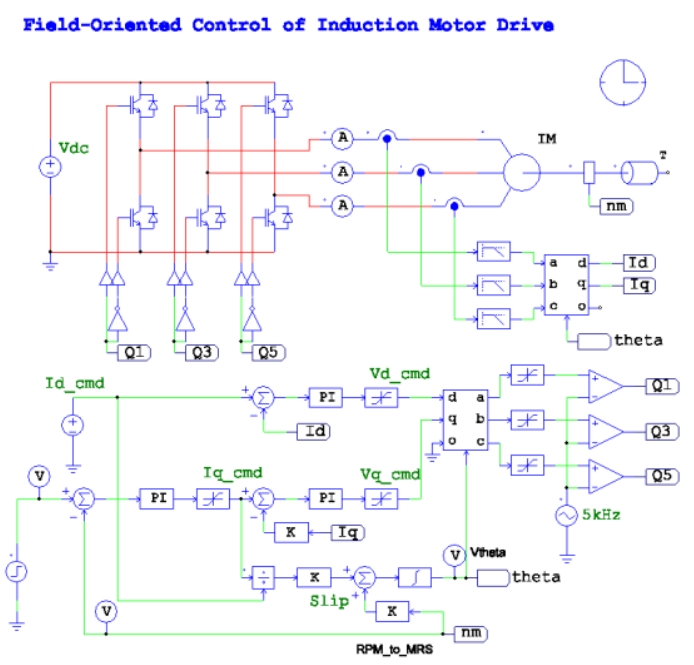

Şekil 3. FOC yöntemi ile sürülen indüksiyon motor sürücüsünün simülasyon şeması.

$\mathrm{Bu}$ simülasyonda, s-domeninde bir endüksiyon motorunun alan odaklı kontrolü uygulanmaktadır ("Field Oriented Control of Induction Motor Drive,"). Alan odaklı kontrol yöntemi (FOC) temel olarak AC bir motorun DC motor eşleniğine çevirerek sanki DC motor kontrol yapılıyormuş gibi kontrol edilebilmesi olarak tanımlanır. $\mathrm{Bu}$ yöntemde ilk olarak çıkış akımlarının örnekleri Şekil 4 'te gösterildiği üzere alınır ve Clarke- Park dönüşümlerini bir arada gerçekleştiren araca verilir. Burada dönüşüm formüllerinde kullanılan Theta açısı da aynı araca verilir. Böylece çıkış akımlarının Id ve Iq olarak elde edilir.

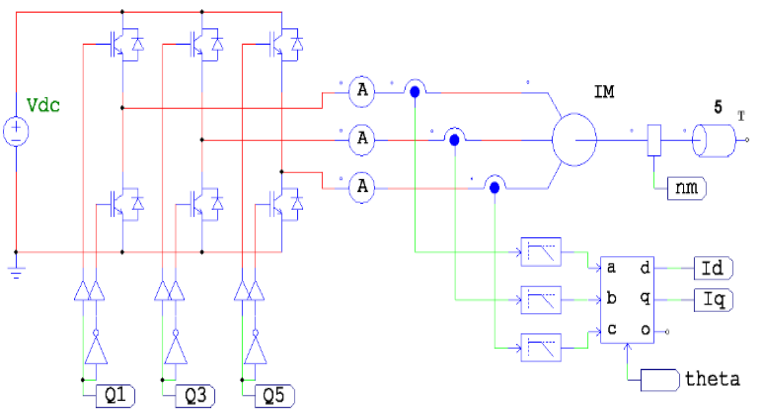

Şekil 4. İndüksiyon motor sürücünün simülasyonu çıkış akım örneklemesi

Clarke-Park dönüşümleri sonucunda elde edilen Id ve Iq akımları Şekil 5'te gösterilen geri besleme ve kontrol döngüsüne kullanılmaktadır. Burada hız kontrolü Iq akımı üzerinden kontrol edilir. Sabit tork olan bu sistemde Id akımı ile aktif işlem yapılmaz. Akıma sadece belirli bir referans ile karşılaştırılması gerçekleştirilerek PI uygulanır. Ayrıca Id akımı Theta açısının hesaplanmasında da kullanılmaktadır. 


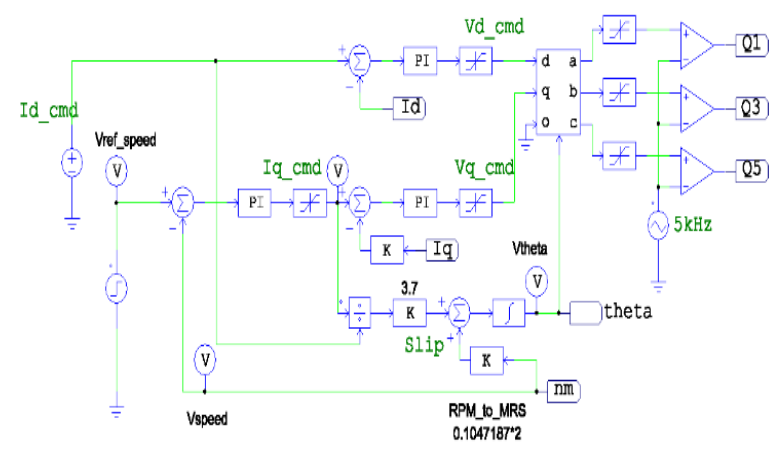

Şekil 5. İndüksiyon motor sürücünün simülasyonu geri besleme kontrol döngüsü

Hız kontrolünün sağlanması için Theta açısının hesaplanması gerekir. $\mathrm{Bu}$ açı hesaplanırken şu yollar izlenir:

Motorun milinden RPM olarak okunan hız bilgisi açısal hıza ( $\mathrm{Rad} / \mathrm{s})$ çevrilir. Bu dönüşüm işlemi aşağıdaki gibidir.

$$
\text { Açısal hız }=\left(\mathrm{rpm}^{*} \mathrm{p} * 2 \pi\right) / 60
$$

Formülde kullanılan “p” çift kutup sayısıdır.

Hız referansı ile hız arasındaki fark alınarak hata elde edilir. $\mathrm{Bu}$ hata PI aracından geçiril ve Id değerine bölünür.

Elde edilen sonuç "Rotor Zaman Sabiti” ile çarpılarak daha evvelden elde edilen açısal hız ile toplanır. Rotor zaman sabiti formülü aşağıdaki gibidir:

Rotor Zaman Sabiti =R_r $/\left(\mathrm{L} \_m+L \_r\right)$

Burada $\mathrm{Rr}$ rotor sargı direncini, Lm motor manyetik endüktansını, Lr rotor sargılarının kaçak endüktansını göstermektedir.

Böylece Theta açısı elde edilmiş olur.

Iq akımı elde edilen hız hatası ile toplanarak Id akımı ile Park- Clarke dönüşümüne koyulur. Yukarıda elde edilen Theta açısı da aynı dönüşüm aracına verilerek Ia, Ib ve Ic akımları elde edilir. Elde edilen faz akımlarının her biri ayrı bir amplifikatörde $5 \mathrm{kHz}$ 'lik testere dişi dalga ile karşılaştırılarak inverter kontrol sinyalleri elde edilir. Buradaki $5 \mathrm{kHz}$ 'lik testere dişi dalga inverterin anahtarlama frekansıdır. Elde edilen kontrol sinyalleri üst kollardaki IGBT 'lere ve ters dalga şekilleri alt kol IGBT 'lere verilerek kontrol sağlanmış olur. Simülasyon olduğundan dolayı kontrol sinyallerindeki ölü zaman otomatik olarak ayarlanır. Her iki simülasyondaki motor değerleri sırasıyla Şekil 6 'da ve her iki simülasyonun karşılaştırılabilmesi için çalıştırma parametreleri Tablo 1'de gösterilmiştir.

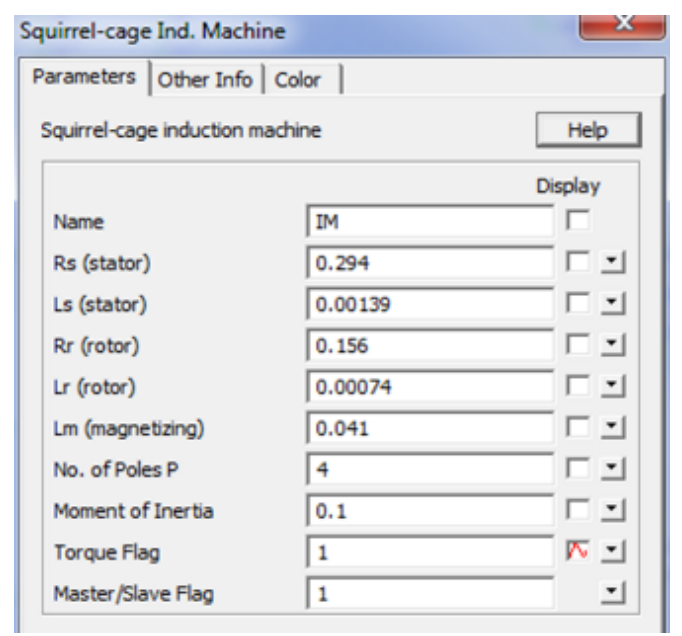

(a)

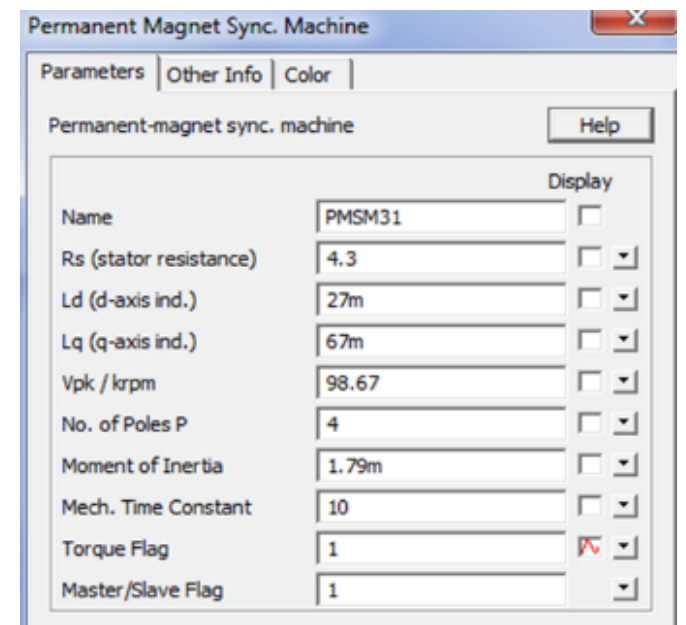

(b)

Şekil 6. Sabit mıknatıslı motor ve indüksiyon motor parametreleri

Tablo 1. Simülasyon parametreleri

\begin{tabular}{|c|c|}
\hline Parametre İsmi & $\begin{array}{c}\text { Parametre } \\
\text { Değeri }\end{array}$ \\
\hline $\begin{array}{c}\text { Anahtarlama } \\
\text { frekansı }\end{array}$ & $5 \mathrm{kHz}$ \\
\hline Yüklenme torku & $5 \mathrm{~N} / \mathrm{m}$ \\
\hline $\begin{array}{c}\text { Başlangıç hız } \\
\text { değeri }\end{array}$ & $170 \mathrm{rpm}$ \\
\hline \begin{tabular}{c} 
İkinci hız değeri \\
\hline $\begin{array}{c}\text { Üçüncü hız } \\
\text { değeri }\end{array}$
\end{tabular} & $85 \mathrm{rpm}$ \\
\hline Giriş gerilimi & $500 \mathrm{~V}_{\mathrm{dc}}$ \\
\hline
\end{tabular}




\section{SIMUÜLASYON SONUÇLARI}

PSIM simülasyon programında her iki motor için aynı tork değerinde hızlar Tablo 1 'deki değerlere göre değiştirilecek çalıştırılmıştır. Her iki motorun aynı şartlar altında hız değişikliklerine verdikleri tepki gözlemlenmiştir. Şekil 7'de FOC kontrolündeki indüksiyon motorunun faz akımları, referans hızı ve gerçek hızı verilmiştir.

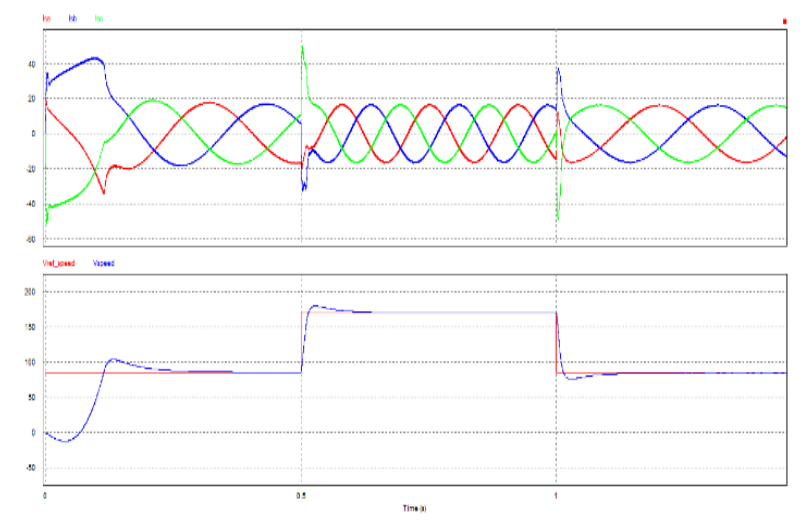

Şekil 7. FOC kontrolündeki indüksiyon motorunun faz akımları, referans hızı ve gerçek hızı dalga şekilleri

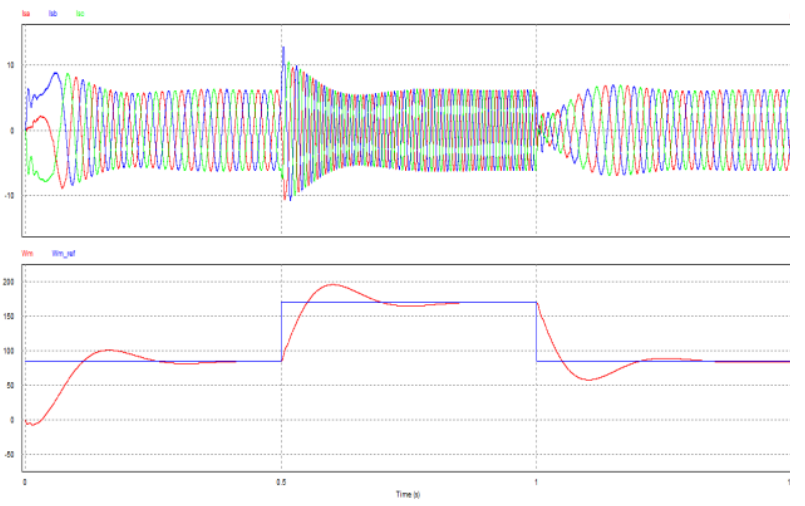

Şekil 8. PWM kontrolündeki PMSM faz akımları, referans hızı ve gerçek hızı dalga şekilleri

Her iki motorun sabit tork altında hız değişimlerinin dalga şekilleri incelendiğinde başlangıçtaki ilk kalkış anındaki torku sabit mıknatıslı senkron motorun $32 \mathrm{~ms}$ yendiği gözlemlenirken indüksiyon motoru $68 \mathrm{~ms}$ 'de yendiği gözlenmektedir. Yani Sabit mıknatıslı motor kalkış torkunu indüksiyon motora göre yaklaşık iki kat daha hizlı yenmektedir.

Motorların hız değişimi incelendiğinde sabit mıknatıslı motor, hız değişimi esnasında yeni hız değerine oturması yaklaşık $350 \mathrm{~ms}$ almaktadır. $\mathrm{Bu}$ süre indüksiyon motorunda $140 \mathrm{~ms}$ 'dir. Yani indüksiyon motoru hız değişimlerine sabit mıknatıslı motorlara göre daha hızlı adapte olabilmektedir.
Motorların hız geçişleri esnasında istedikleri akımlar karşılaştırıldığında indüksiyon motoru nominal çalışması pik akımı 16A iken 170 rpm hıza çıkış esnasında kısa sürelide olsa 50A akım istemektedir. Sabit mıknatıslı motor nominal pik akımı 6.2A iken hız geçişi esnasında maksimum $12.8 \mathrm{~A}$ istemektedir. İndüksiyon motorlarının bu şartlar altında daha kuvvetli bir sürücüye ihtiyacı olmaktadır.

$\mathrm{Bu}$ sonuçlar indüksiyon motorunun hız istenen yerlerde daha etkili olduğu ve sabit mıknatıslı motorlarında daha çok tork istenen uygulamalarda etkili olduğu ispatlanmış olmaktadır.

\section{KAYNAKLAR}

[1] Bălţăţanu, A., \& Florea, L. M. (2013). Comparison of electric motors used for electric vehicles propulsion. Paper presented at the Proceeding of International Conference of Scientific Paper AFASES.

[2] Buyukdegirmenci, V. T., Bazzi, A. M., \& Krein, P. T. (2014). Evaluation of induction and permanent-magnet synchronous machines using drive-cycle energy and loss minimization in traction applications. IEEE Transactions on industry applications, 50(1), 395-403.

[3] Chau, K. (2016). Overview of Electric Vehicle Machines-From Tesla to Tesla, and Beyond. Paper presented at the 2016 International Conference of Asian Union of Magnetics Societies (ICAUMS).

[4] Chau, K., Chan, C. C., \& Liu, C. (2008). Overview of permanent-magnet brushless drives for electric and hybrid electric vehicles. IEEE Transactions on industrial electronics, 55(6), 2246-2257.

[5] El-Refaie, A. M., \& Jahns, T. M. (2005). Optimal flux weakening in surface PM machines using fractional-slot concentrated windings. IEEE Transactions on industry applications, 41(3), 790-800.

[6] El-Refaie, A. M., \& Jahns, T. M. (2008). Comparison of synchronous PM machine types for wide constant-power speed range operation. COMPEL-The international journal for computation and mathematics in electrical and electronic engineering, 27(5), 967-984.

[7] Field Oriented Control of Induction Motor Drive. Retrieved

from https://powersimtech.com/applications/induction -motor-field-oriented-control/

[8] Hashemnia, N., \& Asaei, B. (2008). Comparative study of using different electric motors in the electric vehicles. Electrical Machines, 2008. ICEM 2008. 18th International Conference on, 15.

[9] Kiran, I., Nair, A., \& Lakshmi, S. (2016). Permanent Magnet Synchronous Motor Control with Speed Feedback Using a Resolver. 3(4). 
[10] Kristiansen, K., \& Steinsland, K. E. (2018). PSIM-Based Hardware and Software Design of an Inverter-Fed Permanent Magnet Synchronous Motor. University of Agder.

[11]Murphy, J. What's the Difference Between AC Induction, Permanent Magnet, and Servomotor Technologies? Retrieved from https://www.machinedesign.com/motorsdrives/w hats-difference-between-ac-inductionpermanent-magnet-and-servomotortechnologies. (2012).

[12] Pellegrino, G., Vagati, A., Boazzo, B., \& Guglielmi, P. (2012). Comparison of induction and PM synchronous motor drives for EV application including design examples. IEEE Transactions on industry applications, 48(6), 2322-2332.

[13]Qinghua, L. (2005). Analysis, design and control of permanent magnet synchronous motors for wide-speed operation. National University of Singapore.
[14] Westenhaus, B. The Best Electric Vehicle Motor. Retrieved from https://newenergyandfuel.com/http:/newenergya ndfuel/com/2010/02/09/the-best-electric-vehiclemotor/(2010).

[15] Yang, Z., Shang, F., Brown, I. P., \& Krishnamurthy, M. (2015). Comparative study of interior permanent magnet, induction, and switched reluctance motor drives for $\mathrm{EV}$ and HEV applications. IEEE Transactions on Transportation Electrification, 1(3), 245-254.

[16]Zhang, Y., Cao, W. P., \& Morrow, J. (2015). Interior permanent magnet motor parameter and torque ripple analysis for EV traction. Applied Superconductivity and Electromagnetic Devices (ASEMD), 2015 IEEE International Conference on, 386-387.

[17]Zhu, Z.-Q., \& Howe, D. (2007). Electrical machines and drives for electric, hybrid, and fuel cell vehicles. Proceedings of the IEEE, 95(4), 746-765. 